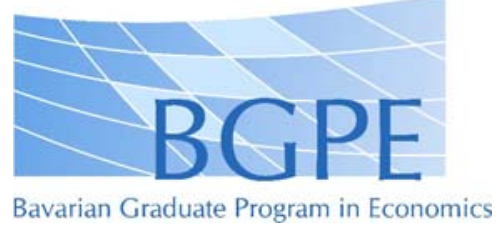

BGPE Discussion Paper

No. 31

\title{
A Dual Elasticity of Substitution Production Function with an Application to Cross Country Inequality
}

\section{Juergen Antony}

\section{August 2007}

ISSN 1863-5733

Editor: Prof. Regina T. Riphahn, Ph.D.

Friedrich-Alexander-University Erlangen-Nuremberg

(c) Juergen Antony 


\title{
A Dual Elasticity of Substitution Production Function with an Application to Cross Country Inequality
}

\author{
Jürgen Antony \\ Department of Economics, University of Augsburg, \\ Universitätsstraße 16, D-86159 Augsburg, Germany \\ e-mail: juergen.antony@wiwi.uni-augsburg.de \\ Tel.: $++49(0) 821-598-4201$ \\ Fax: $++49(0) 821-598-4231$
}

August 9, 2007

\begin{abstract}
This paper develops a production function which two separate elasticities of substitution between two input factors. One of these elasticities is obtained if the factor intensity equals a particular baseline value. The second part of the paper gives an economic application and shows the theoretical properties of this production function regarding the development of relative capital intensities and relative production per efficiency unit of labor. Inequality across countries widens in transition to the steady state. Panel data on the development of these relative figures seem to support the implications of the above production function.
\end{abstract}

Keywords: Capital and labor substitution, cross country inequality JEL Classification Number: O11, O33, E23 


\section{Introduction}

The Cobb-Douglas production function in capital and labor plays an important role in many growth models with all its implications originating from an elasticity of substitution of exactly one. However, already Arrow et al. (1961) noted that this elasticity might change during the process of economic development. Empirical studies also find evidence of departure from a unit elasticity. Recent estimates of the elasticity of substitution for an aggregate production function comes from Duffy and Papageorgiou (2000) who find elasticities below unity for poor and above for rich countries using a panel of 82 countries. Using the same data, Karagiannis et al. (2005) find evidence for a variable elasticity of substitution.

This paper introduces a new production function with a dual elasticity of substitution building on the idea of normalizing a CES production function of De la Grandville (1989). The second section of the paper gives an economic application of this production function in the context of cross country inequality. Two propositions state that during a rise in the capital intensity of the technological leading country, follower countries experience a fall in relative capital intensity and relative production per efficiency unit of labor. A more descriptive analysis shows that these correlation patterns can be found in a panel of countries. Finally section three concludes.

\section{Theoretical Background}

The CES function developed in Arrow et al. (1961) as a solution to the partial differential equation defining the constant elasticity of substitution

$$
\sigma=\frac{f^{\prime}(k)\left[f(k)-k f^{\prime}(k)\right]}{-k f^{\prime \prime}(k) f(k)}
$$

takes the form

$$
f(k)=\gamma_{1}\left[k^{\frac{\sigma-1}{\sigma}}+\gamma_{2}\right]^{\frac{\sigma}{\sigma-1}}
$$

$k$ is defined as capital per efficiency unit of labor, $k=\frac{K}{A L}$, where $K$ is the capital stock, $L$ is raw labor and $A$ might be interpreted as human capital. $f(k)$ is the 
intensive form of a constant returns to scale production function for final output $Y$, $Y=F(A L, K) . f^{\prime}(k)$ and $f^{\prime \prime}(k)$ denote first and second derivatives with respect to $k$. Finally $\gamma_{1}$ and $\gamma_{2}$ are arbitrary constants of integration. De la Grandville (1989) introduced the normalizes CES function through determination of these two constants from initial conditions on production. It is important to note that "initial" is not to be interpreted in terms of time, but in terms of some baseline values for production. If the economy departs from this baseline, the elasticity of substitution is given by $\sigma$. The initial condition were given by $k_{0}, \mu_{0}$ and $y_{0}$, i.e. the baseline capital intensity, the baseline marginal rate of substitution between labor and capital and the baseline production per efficiency unit of labor. For $\gamma_{1}$ and $\gamma_{2}$ this implies

$$
\begin{aligned}
\gamma_{1} & =y_{0} \frac{k_{0}^{\frac{1}{\sigma-1}}}{k_{0}+\mu_{0}}, \\
\gamma_{2} & =\mu_{0} k_{0}^{-\frac{1}{\sigma}} \\
\mu_{0} & =\frac{f\left(k_{0}\right)-k_{0} f^{\prime}\left(k_{0}\right)}{f^{\prime}\left(k_{0}\right)} .
\end{aligned}
$$

The resulting normalized production function was subsequently used by, among others, Klump and De la Grandville (2000) and Klump and Preissler (2000).

An innovative production function can be obtained from these result by explicitly specifying $\mu_{0}$ and $y_{0}$. The economic intuition behind this that the baseline values of production correspond to a situation where the economy is in an optimal position to use the available technology, i.e. if the capital intensity equals $k_{0}$, production possibilities are better than with $k \neq k_{0}$. One way to formalize this idea is to use the specifications:

$$
\begin{aligned}
& \mu_{0}=\frac{\alpha}{1-\alpha} k_{0}^{\frac{\sigma-1}{\sigma}-\frac{\tilde{\sigma}-1}{\tilde{\sigma}}}, \\
& y_{0}=\left[(1-\alpha) k_{0}^{\frac{\tilde{\sigma}-1}{\tilde{\sigma}}}+\alpha\right]^{\frac{\tilde{\sigma}}{\tilde{\sigma}-1}} .
\end{aligned}
$$

This results in the production function

$$
f(k)=\left[(1-\alpha) k_{0}^{\frac{\tilde{\sigma}-1}{\tilde{\sigma}}}+\alpha\right]^{\frac{\tilde{\sigma}}{\tilde{\sigma}-1}\left(1-\frac{\tilde{\sigma}-1}{\tilde{\sigma}} \frac{\sigma}{\sigma-1}\right)}\left[(1-\alpha)\left(\frac{k}{k_{0}}\right)^{\frac{\sigma-1}{\sigma}} k_{0}^{\frac{\tilde{\sigma}-1}{\tilde{\sigma}}}+\alpha\right]^{\frac{\sigma}{\sigma-1}}
$$


in intensive form ${ }^{1}$. If $k$ equals $k_{0}$, this function reduces to $y_{0}$ given by (7) above. This implies that at $k=k_{0}$ the elasticity of substitution equals $\tilde{\sigma}$ and for $k \neq k_{0}$ it is given by $\sigma$.

\section{Cross Country Inequalities}

In this section two propositions regarding inequality are given and empirically tested.

\subsection{Theoretical Implications of a Dual Elasticity}

This section considers a world economy consisting of two countries, a developed and a less developed economy. The developed country is assumed to be the technology leader which sets the technology standards. In the sense of the above production function, this implies that this country can set the baseline value $k_{0}$, thus $k_{0}$ is interpreted as a technological choice variable. It is easy to show that unit costs of production are minimized by choosing $k_{0}=k$ if $\tilde{\sigma}>\sigma$ so that this economy always faces an elasticity of substitution equal to $\tilde{\sigma}$. If the less developed country wants to produce the same final good, it has to adopt the same production techniques as the developed economy, thus, it has to accept the leader's choice of $k_{0}$. In the light of the findings in Duffy and Papageorgiou (2000), the case $\sigma<1<\tilde{\sigma}$ is explored in the following.

The developed and the less developed country differ in their endowments of human capital. Let $A_{0}(A)$ denote the human capital in the developed (less developed) country, where $A<A_{0}$ holds. It is assumed that capital goods used in the production of final goods are produced from foregone consumption of final goods and must meet the human capital standard of the particular country. Thus investments transform into capital goods for the developed and less developed economy according to

$$
\begin{aligned}
K_{0} & =\frac{A_{0}}{\max \left(A, A_{0}\right)} I_{0}, \\
K & =\frac{A}{\max \left(A, A_{0}\right)} I,
\end{aligned}
$$

\footnotetext{
${ }^{1}$ A somehow related production function appears in Jones (2003), where the baseline production is restricted to the Cobb-Douglas case
} 
where $I_{0}(I)$ denote investments of final output in the developed (less developed) economy and $K_{0}(K)$ the corresponding capital stock ${ }^{2}$. The leading level of human capital reduces the amount of capital goods that can be produced from investments due to technology requirements. However, a high level of human capital in the investment receiving country lowers the amount of investments needed. If a country is close to (far from) the technology leader, it has a high (low) degree of compatibility and capital goods can be produced with a similar (different) productivity. This assumption is similar to the assumptions on distance to frontier in Acemoglu et. al (2006), where intermediate input factors produced from final goods in a particular firm have a productivity gap according to the firm's distance to the productivity frontier. Here the assumption is transferred to the production of capital goods.

Since goods and capital market integration demands prizes and the return to investment to equalize, i.e. the investor earns the same rate of interest, regardless where she invests, no arbitrage implies

$$
f^{\prime}\left(k_{0}\right)=f^{\prime}(k) \frac{A}{A_{0}} .
$$

This gives the first result that the technology leader enjoys the higher elasticity $\tilde{\sigma}$ and the less developed country the lower elasticity $\sigma$. Due to the lower level of human capital, the less developed country needs a higher marginal product of capital to meet interest standards and hence a lower capital intensity than $k_{0}$. From the result (11) and the production function (8) it follows that

$$
\begin{aligned}
\frac{A}{A_{0}} & =\left(\frac{f(k) / k}{f\left(k_{0}\right) / k_{0}}\right)^{-\frac{1}{\sigma}} \\
\frac{k}{k_{0}} & =\left[\left(\frac{A}{A_{0}}\right)^{-(\sigma-1)}\left(\frac{1-\alpha}{\alpha} k_{0}^{\frac{\tilde{\sigma}-1}{\tilde{\sigma}}}+1\right)-\frac{1-\alpha}{\alpha} k_{0}^{\frac{\tilde{\sigma}-1}{\tilde{\sigma}}}\right]^{-\frac{\sigma}{\sigma-1}} .
\end{aligned}
$$

From (13) some further results can deduced.

Proposition 1: If $\sigma<1<\tilde{\sigma}$ and $A<A_{0}$ it directly follows that the relative capital intensity of the less developed country decreases with the capital intensity $k_{0}$ of the developed economy.

\footnotetext{
${ }^{2}$ It is assumed that investments are fully reversible.
} 
Proof: Differentiation (13) with respect to $k_{0}$ gives

$$
\frac{\partial \frac{k}{k_{0}}}{\partial k_{0}}=-\frac{\tilde{\sigma}-1}{\sigma-1} \frac{\sigma}{\tilde{\sigma}} \frac{1-\alpha}{\alpha}\left(\frac{k}{k_{0}}\right)^{-\frac{2 \sigma-1}{\sigma}}\left[\left(\frac{A}{A_{0}}\right)^{-(\sigma-1)}-1\right] k_{0}^{-\frac{1}{\tilde{\sigma}}},
$$

which is always negative if the above conditions are satisfied

Turning to the relative production per efficiency unit of the less developed country, $\frac{f(k)}{f\left(k_{0}\right)}$, the following proposition gives the reaction of the relative per capita production with respect to changes in per capita production in the developed country.

Proposition 2: If $\sigma<1<\tilde{\sigma}$ and $A<A_{0}$ it directly follows that the relative production per efficiency unit of the less developed country decreases with a rising production per efficiency unit in the developed economy.

Proof: First note that $\frac{f(k) / k}{f\left(k_{0}\right) / k_{0}}$ must be constant according to (12). Building the total differential of this expression gives

$$
\frac{k_{0}}{k} d \frac{f(k)}{f\left(k_{0}\right)}-\frac{f(k)}{f\left(k_{0}\right)}\left(\frac{k_{0}}{k}\right)^{2} \frac{\partial \frac{k}{k_{0}}}{\partial k_{0}} \frac{\partial k_{0}}{\partial f\left(k_{0}\right)} d f\left(k_{0}\right)=0 .
$$

which can be rearranged as

$$
\frac{d \frac{f(k)}{f\left(k_{0}\right)}}{d f\left(k_{0}\right)}=\frac{f(k)}{f\left(k_{0}\right)} \frac{k_{0}}{k} \frac{\partial \frac{k}{k_{0}}}{\partial k_{0}} \frac{\partial k_{0}}{\partial f\left(k_{0}\right)} .
$$

Since $\frac{\partial \frac{k}{k_{0}}}{\partial k_{0}}<0$ by proposition 1 , relative production per efficiency unit in the developed country decreases as production per efficiency unit in the developed country increases

Note that these results would never be obtained if both countries would share the same elasticity of substitution. These two propositions are extremely relevant during a period of adjustment of the developed economy to a steady state from below. During this phase, the capital intensity as well as the production per efficiency unit increase. Subsequently the capital intensity and production per efficiency unit in the less developed country rise as well but at a lower rate than in the developed economy. This happens because both the rise of $k_{0}$ and $k$ lower the interest rate in the less developed country and thus the rise in $k$ need not to be so large as in $k_{0}$ to restore equilibrium. The technology choice of the developed country has a negative impact on the the marginal product of capital in the less developed country, requiring less additional capital allocation to reach the equilibrium interest rate. 


\subsection{Data and Empirical Relationships}

Propositions one and two above show that a production function with a dual elasticity of substitution as (8) can cause severe trends in inequality during a period of increasing capital intensity of a technology setting country. This sections tries to find support for this findings by presenting some more descriptive results.

The data used are from the Penn World Tables Mark 5.6 (see Heston and Summers 1991) for the period 1950 to 1992. From this database an unbalanced panel of 64 countries with in total 1673 observations in capital intensities can be extracted. The variable used is KAPW which the capital intensity in 1985 international prices. To obtain a measure of relative production inequality from the Penn World Tables one has to rely on GDP per worker (variable RGDPW, measured in 1985 international prizes). There are considerably more observations available on GDP per worker, resulting in an unbalanced panel of 146 countries with in total 4687 observations. As the technology leader the U.S. were chosen since the U.S. possesses the highest capital intensity.

To get an impression about the relationships between these variables, three regressions with country fixed effects were run. Dependent variable is the annual growth rate of the relative capital intensity, $\frac{\hat{k_{i}}}{k_{0}}$, one regression contains just the annual growth rate of the U.S. capital intensity, the other additionally the log of the relative capital intensity and/or relative GDP per worker as a controls. Analogous regressions were run for the growth rate of relative GDP per worker, $\frac{\hat{y_{i}}}{y_{0}}$. For $k_{0}$ and $y_{0}$ the values for the U.S. were chosen.

Because the capital intensity and per capita GDP from the Penn World Table deviate from the theoretical concept above due to the missing human capital component, country fixed effects were included in the regressions in growth rates to allow for country specific trends in human capital. The regressions are meant to provide some insights into the correlation structure of the relevant variables rather than to provide estimation results of structural relationships. Table 1 presents the results.

As can be seen, all the correlations of interest are negative and in accordance with the above propositions. The control variable relative capital intensity has always a 
Table 1: Estimation Results

\begin{tabular}{|c|c|c|c|c|c|c|}
\hline Dependent variable: & $\frac{\hat{k_{i}}}{k_{0}}$ & $\frac{\hat{k_{i}}}{k_{0}}$ & $\frac{\hat{k_{i}}}{k_{0}}$ & $\frac{\hat{y_{i}}}{y_{0}}$ & $\frac{\hat{y_{i}}}{y_{0}}$ & $\frac{\hat{y_{i}}}{y_{0}}$ \\
\hline$\hat{k_{0}}$ & $\begin{array}{l}-0.437 \\
{[0.053] * * *}\end{array}$ & $\begin{array}{l}-0.5355 \\
{[0.162]^{* * *}}\end{array}$ & $\begin{array}{l}-0.449 \\
{[0.060]^{* * *}}\end{array}$ & - & - & - \\
\hline $\ln \left(k_{i} / k_{0}\right)$ & - & $\begin{array}{l}-0.020 \\
{[0.012]^{*}}\end{array}$ & $\begin{array}{l}-0.060 \\
{[0.006]^{* * *}}\end{array}$ & - & - & $\begin{array}{l}-0.090 \\
{[0.0163] * * *}\end{array}$ \\
\hline$\hat{y}_{0}$ & - & - & - & $\begin{array}{l}-0.819 \\
{[0.103]^{* * *}}\end{array}$ & $\begin{array}{l}-0.785 \\
{[0.116]^{* * *}}\end{array}$ & $\begin{array}{l}-0.716 \\
{[0.132]^{* * *}}\end{array}$ \\
\hline $\ln \left(y_{i} / y_{0}\right)$ & - & - & $\begin{array}{l}0.069 \\
{[0.007]^{* * *}}\end{array}$ & - & $\begin{array}{l}0.023 \\
{[0.007]^{* * *}}\end{array}$ & $\begin{array}{l}0.109 \\
{[0.016]^{* * *}}\end{array}$ \\
\hline Obs. & 1673 & 1673 & 1564 & 4687 & 4687 & 1629 \\
\hline Countries & 64 & 64 & 64 & 146 & 146 & 64 \\
\hline$R^{2}$ & 0.336 & 0.345 & 0.394 & 0.148 & 0.153 & 0.259 \\
\hline
\end{tabular}

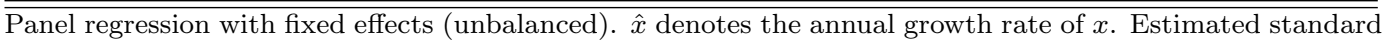
errors in brackets (heteroskedastity consistent). * (**,***) denotes significance at the 10\% (5\%, 1\%) level of significance.

negative, the relative GDP per worker a positive estimated coefficient. However, if both controls are included the coefficient for relative GDP per capita is always larger in absolute magnitude. These results raughly indicate that the negative correlations mentioned above are counteracted if a country converges against the baseline values of the U.S. These results seem to support the the hypotheses that the empirically observed difference in the elasticity of substitution between labor and capital has important implications for inequality across countries.

\section{Conclusion}

An innovative production function based on the insights of De la Grandville (1989) has been proposed with a dual elasticity of substitution between input factors. Although the elasticity of substitution changes only at one specific point, an economic example interpreting this point as a technology choice variable gives this production function its relevance. The implications of a dual elasticity is in accordance with empirical findings and can explain widening inequality concerning per capita production and capital intensity of production. During transition to equilibrium, the capital intensity and production per efficiency unit of labor grow faster in developed than in less developed countries. Theoretically the distinction between developed and less developed is drawn with respect to a human capital variable. If this variable takes on the same value for all countries, this unequal development disappears. 


\section{Literature}

Acemoglu, D, Phillipe Aghion and F. Zilibotti (2006): Distance to Frontier, Selection, and Economic Growth. Journal of the European Economic Association, $4,37-74$.

Arrow, K. J., H. B. Chenery, B. S. Minhas and R. M. Solow(1961): Capital-Labor Substitution and Economic Efficiency. Review of Economics and Statistics, $43,225-250$.

Duffy, J. and C. Papageorgiou (2000): A Cross-Country Empirical Investigation of the Aggregate Production Function Specification. Journal of Economic Growth, 5, 87-120.

Heston, A. and R. Summers (1991): The Penn World Table (Mark 5): An Expanded Set of International Comparisons, 1950-1988. Quarterly Journal of Economics, $106,327-368$.

Jones, C. I. (2003): Growth, Capital Shares, and a New Perspective on Production Functions. University of California, Berkeley.

Karagiannis, G., T. Palvios and C. Papageorgiou (2005): Variable Elasticity of Substitution and Economic Growth: Theory and Evidence. In: Diebold, C. and C. Kyrtsou (2005): New Trends in Macroeconomics. Springer, Heidelberg.

Klump, R. and O. De la Grandville (2000): Economic Growth and the Elasticity of Substitution: Two Theorems and Some Suggestions. American Economic Review, 90, 282-291.

Klump, R. and H. Preissler (2000): CES Production Functions and Economic Growth. Scandinavian Journal of Economics, 102, 41-56. 